\title{
Improved vascular engraftment and function of autotransplanted pancreatic islets as a result of partial pancreatectomy in the mouse and rat
}

\author{
M. Johansson • L. Jansson • P.-O. Carlsson
}

Received: 21 November 2006 / Accepted: 15 January 2007 / Published online: 4 April 2007

(C) Springer-Verlag 2007

\begin{abstract}
Aims/hypothesis The few patients subjected to autotransplantation of pancreatic islets after pancreatectomy usually become normoglycaemic after using islets from the resected organ only, whereas allogeneic recipients usually require at least two grafts to retain normoglycaemia. Previous experimental studies have demonstrated that islets transplanted to non-pancreatectomised recipients acquire a markedly decreased blood vessel density, which leads to a hypoxic microenvironment. The aim of the present study was to test the hypothesis that autotransplanted islets have better vascular engraftment and function as a result of the pancreatic surgery involved.

Materials and methods In the present study, athymic mice and inbred rats were subjected to a $60 \%$ pancreatectomy and transplanted with human or rat islets, respectively, 4 days later. Control animals underwent sham surgery. Blood flow, oxygen tension, vascular density and endocrine volume in the islet grafts were measured 1 month after transplantation. Separate grafts were used for perfusion experiments and for assessment of beta cell proliferation and endocrine cellular apoptosis at different time periods after transplantation.
\end{abstract}

M. Johansson · L. Jansson • P.-O. Carlsson ( $\varangle)$

Department of Medical Cell Biology, Uppsala University,

Husargatan 3, Box 571, 75123 Uppsala, Sweden

e-mail: per-ola.carlsson@medcellbiol.uu.se

P.-O. Carlsson

Department of Medical Sciences, Uppsala University,

75123 Uppsala, Sweden

Present address:

M. Johansson

Department of Pathology, University of California,

San Francisco, CA 94115, USA
Results Islet grafts in partially pancreatectomised recipients had an increased blood flow, oxygen tension, blood vessel density and endocrine mass 1 month post-transplantation compared with control animals. They also exhibited increased insulin release in perfusion experiments performed 1 month post-transplantation, and decreased cellular apoptosis early after transplantation.

Conclusions/interpretation The present study shows that the pancreatectomy procedure itself has beneficial effects on the engraftment of transplanted human and rat islets. Our results provide an additional explanation, besides diminished immunological responses, of the much better outcome of islet autotransplantations compared with allogeneic transplantations in the clinic.

Keywords Blood flow · Insulin release · Islet graft · Islet transplantation $\cdot$ Oxygen tension $\cdot$ Revascularisation

\author{
Abbreviations \\ BS-1 Bandeiraea simplicifolia \\ GLP-1 glucagon-like peptide-1 \\ REG regenerating gene protein \\ TBS Tris-buffered saline \\ TUNEL terminal deoxynucleotidyl transferase-mediated \\ dUTP-biotin nick-end labelling \\ UE Ulex europaeus \\ VEGF vascular endothelial growth factor
}

\section{Introduction}

Pancreatic islet allogeneic transplantation is a tempting strategy for the treatment of patients with type 1 diabetes. Using the 'Edmonton protocol' [1], a 1-year insulin inde- 
pendence rate of $80 \%$ [2], i.e. comparable to that for whole pancreas transplantation [3], can be obtained. However, whereas one whole pancreas is sufficient to reverse hyperglycaemia [3, 4], two or more pancreases are generally needed to achieve this when isolated islets are transplanted. Moreover, there seems to be a steady decline in the function of islet grafts, with very few patients remaining insulinindependent beyond 4 years after transplantation [5]. Since the histocompatibility barrier, the underlying autoimmune disease, and the immunosuppressive agents used are the same for both transplantation procedures, it is likely that differences in engraftment between whole pancreas and islets can at least partly account for the divergence in the results.

When islets are isolated for transplantation they become disconnected from their vascular supply. Revascularisation of transplanted islets has been shown to occur within 12 weeks $[6,7]$. However, the vascular density of the graft remains lower than that of native islets [8,9], and is associated with impaired oxygenation $[9,10]$ and function [11-13] of the islet tissue.

Clinically, autotransplantation of islets is performed in a few situations e.g. necessity of pancreatectomy for severe chronic pancreatitis or benign pancreatic tumours $[14,15]$. The results after implantation of autologous islets have been strikingly better than those for allogeneically transplanted islets [14, 15]. In fact, only a third of the number of islets seems to be needed to attain a similar degree of insulin independence in the former case $[14,15]$. Long-term graft survival is also markedly better for autotransplanted islets [16].

The marked difference in results between autologous and allogeneic islet transplantation has been interpreted to be due to immunological barriers and treatment with immunosuppressive drugs in the allogeneic setting. However, when performing autologous transplantation, nearly the whole pancreas is removed to isolate the islets [14]. In experimental studies, such pancreatic surgery has been shown to be associated with the regeneration of both the exocrine and the endocrine pancreas, because of the induction of a vast number of growth and survival factors, e.g. vascular endothelial growth factor (VEGF), regenerating gene protein (REG) and glucagon-like peptide-1 (GLP-1) [1721]. Several of the growth factors shown to be induced following pancreatic resection also affect angiogenesis [2224]. The present study therefore aimed to investigate the hypothesis that autotransplanted rat islets and human islets transplanted into partially pancreatectomised recipients become better engrafted than corresponding control islets.

\section{Materials and methods}

Animals Inbred male Wistar-Furth rats and C57BL/6 (nu/nu) mice, 10-15 weeks of age, were used in this study. The animals were purchased from Scanbur (Sollentuna, Sweden) and M\&B (Ry, Denmark), respectively. All experimental procedures were approved by the animal ethics committee of Uppsala University and followed the 'Principles of laboratory animal care' (NIH publication no. 85-23, revised 1985).

Partial pancreatectomy Wistar-Furth rats were anaesthetised with sodium pentobarbital (Apoteket, Göteborg, Sweden; $60 \mathrm{mg} / \mathrm{kg}$ i.p), whereas C57BL/6 (nu/nu) mice were anaesthetised with avertin $(0.02 \mathrm{ml} / \mathrm{g}$ i.p. of a $2.5 \%$ [vol/vol] solution of $10 \mathrm{~g} \mathrm{97 \%} \mathrm{[vol/vol]} \mathrm{2,2,2-tribromo-}$ ethanol [Sigma-Aldrich, St Louis, MO, USA] in $10 \mathrm{ml} 2-$ methyl-2-butanol [Kemila, Stockholm, Sweden]). The animals were placed on a heated operating table. All parts of the pancreas not attached to the stomach or duodenum, hereafter referred to as the splenic part of the gland, were removed [25]. The splenic part of the pancreas constitutes approximately $60 \%$ of the whole gland [25]. Different animals underwent sham surgery, that is, the splenic portion was mobilised, but otherwise not treated.

Islet isolation, culture and transplantation Pancreatic islets were isolated by collagenase digestion [26] from the extirpated part of the pancreas or from the whole pancreas of control Wistar-Furth rats. In some additional control animals, islets from the splenic and duodenal parts of the pancreas were isolated separately. The rat islets were cultured in RPMI 1640 (Sigma-Aldrich) supplemented with $11 \mathrm{mmol} / 1 \mathrm{D}$-glucose, $2 \mathrm{mmol} / 1 \mathrm{~L}$-glutamine (SigmaAldrich) and $10 \%(\mathrm{vol} / \mathrm{vol})$ fetal calf serum (SigmaAldrich) in $95 \%$ air $/ 5 \% \mathrm{CO}_{2}$ at $37^{\circ} \mathrm{C}$ [26] for 4 days. The culture medium was changed every $48 \mathrm{~h}$.

Human islets from nine heart-beating donors (age $51 \pm$ 4 years; four men, five women; BMI range $18.4-27.8 \mathrm{~kg} /$ $\mathrm{m}^{2} ; \mathrm{HbA}_{1 \mathrm{c}}$ international standard range 5.0-5.7\%) were isolated at the Human Islet Isolation Core Facility for the Nordic Countries (Uppsala, Sweden), and were kindly provided by $\mathrm{O}$. Korsgren. Insulin release from the preparations was investigated by islet perifusion prior to delivery, and the mean glucose stimulation index was found to be $11.1 \pm 1.6$ (range $6.7-15.6, n=9$ ). The human islets were kept in culture for 4-7 days in RPMI 1640 medium (Sigma-Aldrich) supplemented with $5.6 \mathrm{mmol} / \mathrm{l}$ D-glucose, $2 \mathrm{mmol} / \mathrm{l} \mathrm{L}$-glutamine (Sigma-Aldrich) and 10\% fetal calf serum prior to transplantation [27]. All experiments involving human islets were approved by the human ethics committee for Uppsala University.

At transplantation, groups of 250 Wistar-Furth islets, or 200 human islets, were packed into a braking pipette and implanted beneath the left renal capsule of syngeneic pentobarbital-anaesthetised (see above) Wistar-Furth rats or avertin-anaesthetised (see above) C57BL/6 (nu/nu) mice, respectively. In five cases, two mice received islets from the 
same human donor, but were then allocated to different groups. Some of the islet recipients had been partially pancreatectomised or sham operated 4 days before transplantation. The different experimental groups are summarised in Table 1.

Oxygen tension and blood flow measurements The WistarFurth rats were anaesthetised with thiobutabarbital (Research Biochemicals, Natick, MA, USA; $120 \mathrm{mg} / \mathrm{kg}$ body weight i.p.), whereas the $\mathrm{C} 57 \mathrm{BL} / 6$ (nu/nu) mice were anaesthetised with avertin (see above). The animals were then prepared for the islet oxygen tension and blood flow measurements $[9,28]$.

Oxygen tension was measured in the islets using modified Clark-type microelectrodes (Unisense, Aarhus, Denmark), as previously described [28]. At least five measurements were performed in all islets.

Islet graft blood perfusion was measured by laserDoppler flowmetry (PF 4001-2; Perimed, Stockholm, Sweden) using a needle probe (411; Perimed) [28]. At least three blood flow measurements were performed in the transplanted islets in each animal. The blood perfusion of native islets cannot be determined by the laser-Doppler technique because they occur singly and not in clusters.

During the oxygen tension and blood flow measurements, blood pressure, body temperature and tissue temperature were continuously recorded with a MacLab Instrument (AD Instruments, Hastings, UK).
Measurements of blood parameters Blood glucose concentrations were determined using test reagent strips (Medisense; Baxter Travenol, Deerfield, IL, USA). Once the blood flow and oxygen tension measurements had been completed, a blood sample was collected for analysis of packed cell volume and blood gases. Animals were excluded if one or more of the following pre-set exclusion criteria were met: packed cell volume $<40, \mathrm{pH}<7.30, \mathrm{pO}_{2}$ $<10 \mathrm{kPa}(75 \mathrm{mmHg})$ and $\mathrm{pCO}_{2}>6.8 \mathrm{kPa}(51 \mathrm{mmHg})$.

Morphological studies The graft-bearing kidneys or the pancreases from control animals were removed after the oxygen tension and blood flow measurements, fixed in $10 \%$ formaldehyde, and then embedded in paraffin. Samples of apparently normal human pancreas, obtained following pancreatectomies, were treated in the same manner. Consecutive $5-\mu \mathrm{m}$ sections were stained for the lectins Bandeiraea simplicifolia (BS-1; both human and rat islets) or Ulex europaeus (UE; human islets only) and counterstained with haematoxylin [9]. We have previously shown that BS-1 produces consistent staining of all blood vessels in rat, mouse and human islets, whereas UE only stains blood vessels of human origin [9]. Moreover, we have previously observed that quantification of BS-1- and UEpositive blood vessels provides identical estimates of the vascular density of native human islets [9]. Hence, we were able to determine the fraction of blood vessels that originated from the donor by comparing the estimated

Table 1 Schematic overview of surgical procedures and parameters investigated

\begin{tabular}{|c|c|c|c|c|c|c|}
\hline & \multicolumn{5}{|c|}{ Surgical procedures } & \multirow{2}{*}{$\begin{array}{l}\text { Parameters investigated } \\
\text { post-transplantation } \\
\text { Day } 30\end{array}$} \\
\hline & $n$ & $\begin{array}{l}\text { Day }-4 \\
\text { Pancreatectomy }\end{array}$ & $\begin{array}{l}\text { Day } 0 \\
\text { Transplantation }\end{array}$ & Day 2 & Day 5 & \\
\hline \multicolumn{7}{|l|}{ Rat islets } \\
\hline AutoTx & 8 & Yes & Yes & & & $\begin{array}{l}\text { Oxygen tension, blood flow, graft volume, } \\
\text { blood vessel density }\end{array}$ \\
\hline PxTx & 33 & Yes & Yes & $\begin{array}{l}\text { Ki67, TUNEL, } \\
\text { plasma VEGF }\end{array}$ & $\begin{array}{l}\text { Ki67, TUNEL, } \\
\text { graft volume }\end{array}$ & $\begin{array}{l}\text { Oxygen tension, blood flow, Ki67, TUNEL } \\
\text { graft volume, blood vessel density }\end{array}$ \\
\hline ShamTx & 35 & Sham surgery & Yes & $\begin{array}{l}\text { Ki67, TUNEL, } \\
\text { plasma VEGF }\end{array}$ & $\begin{array}{l}\text { Ki67, TUNEL, } \\
\text { graft volume }\end{array}$ & $\begin{array}{l}\text { Oxygen tension, blood flow, Ki67, TUNEL } \\
\text { graft volume, blood vessel density }\end{array}$ \\
\hline $\mathrm{Tx}$ & 13 & No & Yes & & & $\begin{array}{l}\text { Oxygen tension, blood flow, blood vessel } \\
\text { density }\end{array}$ \\
\hline $\mathrm{Px}$ & 16 & Yes & No & & & Non-transplanted control \\
\hline Non-operated & 8 & No & No & & & Blood vessel density \\
\hline \multicolumn{7}{|l|}{ Human islets } \\
\hline PxTx & 8 & Yes & Yes & & & $\begin{array}{l}\text { Oxygen tension, blood flow, blood vessel } \\
\text { density }\end{array}$ \\
\hline ShamTx & 8 & Sham surgery & Yes & & & $\begin{array}{l}\text { Oxygen tension, blood flow, blood vessel } \\
\text { density }\end{array}$ \\
\hline
\end{tabular}

AutoTx pancreatectomy followed by autotransplantation of retrieved islets, Px only pancreatectomised animals, PxTx syngeneic transplantation with previous pancreatectomy, Sham $T x$ syngeneic transplantation with previous sham surgery, $T x$ syngeneic transplantation without pancreatectomy 
blood vessel density using BS-1 and UE. The blood vessel density in pancreatic islets and the surrounding stroma was determined using a direct point-counting method on histological sections at $\times 400$ magnification [29]. A total of five sections, or $620 \pm 25$ intersection points, were counted in each transplant or pancreas. Sections were also investigated for infiltration of inflammatory cells in the islets. The total graft volumes and the proportions represented by endocrine cells were estimated using a computerised system for morphometry [30], using updated software (Scion Image; Scion, Frederick, MD, USA).

Ki67 and insulin staining In separate experiments, graftbearing rat kidneys were removed at 2,5 or 30 days posttransplantation, prepared for histology, and then stained for the cell proliferation marker Ki67 according to the manufacturer's instructions (Lab Vision, Fremont, CA, USA). Briefly, antigen retrieval was performed by boiling for $20 \mathrm{~min}$ with citrate buffer $(10 \mathrm{mmol} / \mathrm{l}, \mathrm{pH} 6.0)$ in a microwave oven $(750 \mathrm{~W})$. The sections were washed in Tris-buffered saline (TBS) and thereafter incubated for $1 \mathrm{~h}$ with normal swine serum (Dako, Glostrup, Denmark) diluted 1:20 with TBS containing $0.1 \%(\mathrm{wt} / \mathrm{vol})$ BSA. Primary monoclonal rabbit antibodies directed against Ki67 (1:200 dilution; clone SP6; Lab Vision) diluted in TBS were applied to the slides overnight at $4^{\circ} \mathrm{C}$. The slides were washed (in TBS; $3 \times 5 \mathrm{~min}$ ) and incubated for $1 \mathrm{~h}$ with a swine anti-rabbit antibody (Dako) diluted 1:100 in TBS, and finally developed with 3,3'-diaminobenzidinetetrahydrochloride (Sigma-Aldrich). The sections were thereafter stained for insulin [29] and visualised with Vectastain ABC (Vector Laboratories, Burlingame, CA, USA).

Terminal deoxynucleotidyl transferase-mediated dUTPbiotin nick-end labelling staining Separate slides of sections from rats at 2, 5 or 30 days post-transplantation were prepared for terminal deoxynucleotidyl transferase-mediated dUTP-biotin nick-end labelling (TUNEL) staining, as previously described [31], for detection of apoptotic cells. Briefly, sections were incubated for 15 min with proteinase K (20 $\mu \mathrm{g} / \mathrm{ml}$; Sigma-Aldrich), followed by a 5 -min exposure to $2 \%$ hydrogen peroxide. The sections were then incubated with terminal deoxynucleotidyl transferase (10 enzyme units $/ 50 \mu \mathrm{l}$; Boehringer-Mannheim, Mannheim, Germany) and biotinylated deoxyuridine $(0.5 \mathrm{nmol} /$ $50 \mu \mathrm{l}$; Boehringer-Mannheim) in transferase buffer (30 mmol/1 Tris, pH 7.2, $140 \mathrm{mmol} / 1$ sodium cacodylate and $1 \mathrm{mmol} / 1$ cobalt chloride) for $60 \mathrm{~min}$ at $37^{\circ} \mathrm{C}$. After washing and blocking with $2 \%$ BSA, the sections were incubated with Vectastain $\mathrm{ABC}$ (Vector Laboratories) for $30 \mathrm{~min}$ at room temperature and developed in 3-amino-9ethylcarbazole solution.
Islet graft perfusion Grafts from some of the Wistar-Furth rats that received transplants were investigated 1 month after transplantation for glucose- and arginine-stimulated insulin secretion [32]. The insulin concentrations of the effluent samples were measured by ELISA (Mercodia, Uppsala, Sweden) and multiplied by the flow rate, giving values of insulin expressed as $\mathrm{pmol} / \mathrm{min}$. The AUC was then determined from these values.

Plasma VEGF measurement Blood samples were taken from partially pancreatectomised and sham-operated rats investigated at day 2 post-transplantation. The blood samples were kept on ice, and the protease inhibitor Trasylol (10,000 KIE/ml; Bayer Healthcare, Leverkusen, Germany) was added. Plasma was stored at $-70^{\circ} \mathrm{C}$. The VEGF-A contents in the plasma were determined using a rat VEGF ELISA (R\&D Systems, Minneapolis, MN, USA).

Statistical analysis All values are given as means \pm SEM. Multiple comparisons of normally distributed data with control values were performed using ANOVA and Dunnett's post-hoc test, whereas non-parametric values were compared using non-parametric ANOVA and Dunn's post-hoc test. For pairwise comparisons of normally distributed data, the Student's $t$ test was used. For all comparisons, a $p$ value of $<0.05$ was considered to be statistically significant.

\section{Results}

Animal data All animals allocated to the study were normoglycaemic $(5.6 \pm 0.1 \mathrm{mmol} / \mathrm{l}$ for the rats, $n=120 ; 6.9 \pm$ $0.2 \mathrm{mmol} / 1$ for the mice, $n=12$ ). The Wistar-Furth rats weighed approximately $300 \mathrm{~g}$ and the C57BL/6 (nu/nu) mice weighed $25-30 \mathrm{~g}$. The resected part of the pancreas weighed $477 \pm 11 \mathrm{mg}$ and $127 \pm 4 \mathrm{mg}$ in the rats $(n=43)$ and mice $(n=6)$, respectively. All animals subjected to partial pancreatectomy or sham surgery remained normoglycaemic on the day of islet transplantation $(5.5 \pm 0.1[n=31]$ vs $5.7 \pm 0.1 \mathrm{mmol} / 1[n=34]$ for the two groups of rats, respectively and $6.9 \pm 0.3[n=6]$ vs $7.0 \pm 0.3 \mathrm{mmol} / 1[n=6]$ for the two groups of mice, respectively), as well as at days 2, 5 and 30 after transplantation (data not shown). The body weight increase was similar in animals subjected to a partial pancreatectomy or sham operation, as evaluated 1 month post-transplantation $(18.4 \pm 2.6 \%[n=9]$ vs $15.8 \pm 2.7 \%[n=8]$ for the rats, and $12.5 \pm 2.5 \%[n=6]$ vs $9.0 \pm 3.2 \%[n=6]$ for the mice). At the time of the oxygen tension and blood flow measurements, mean arterial blood pressure was approximately $110 \mathrm{mmHg}$ in the rats and 90 $100 \mathrm{mmHg}$ in the mice, and did not differ between the 


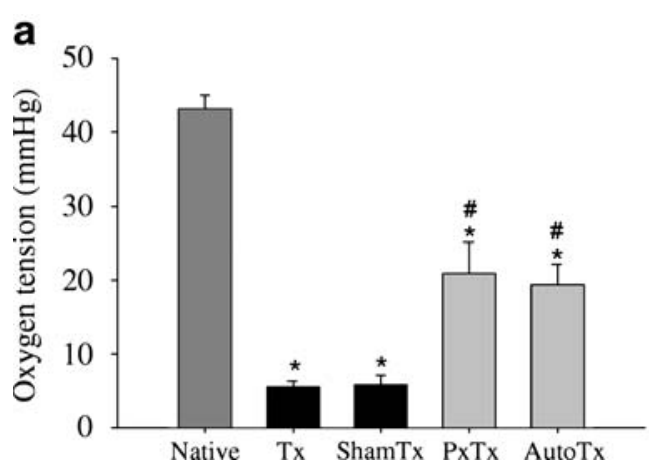

Fig. 1 Oxygen tension in native and transplanted rat islets (a) and human islets transplanted into $n u / n u$ mice (b) as measured by Clark microelectrodes at day 30 post-transplantation. Experimental groups: syngeneic transplantation $(T x)$, syngeneic transplantation with previous

experimental groups. There were no signs of inflammatory reactions in the pancreas of any of the investigated partially pancreatectomised or sham-operated animals, as judged from the haematoxylin-stained histological sections, and no animals were excluded from the study based on the pre-set exclusion criteria regarding blood gases and packed cell volumes $\left(\mathrm{pO}_{2}\right.$ range $10.2-12.1 \mathrm{kPa}$ and $10.4-$ $11.9 \mathrm{kPa}, \mathrm{pCO}_{2}$ range $4.1-6.5 \mathrm{kPa}$ and $4.5-6.7 \mathrm{kPa}$, packed cell volume ranges $44-52 \%$ and $47-53 \%$ in rats and mice, respectively).

Oxygen tension The oxygen tension was $40-45 \mathrm{mmHg}$ $(5.3-6.0 \mathrm{kPa})$ in native rat islets, but only $4-7 \mathrm{mmHg}(0.5-$ $0.9 \mathrm{kPa}$ ) in 1-month-old syngeneic control rat islet transplants (Fig. 1a). However, the oxygen tension in the islet transplants of autotransplanted or partially pancreatectomised recipients was three- to fourfold higher than that in the corresponding control animals. The oxygen tension in transplants composed of islets derived from the splenic portion of the donor pancreas did not differ from that in transplants composed of islets derived from the duodenal

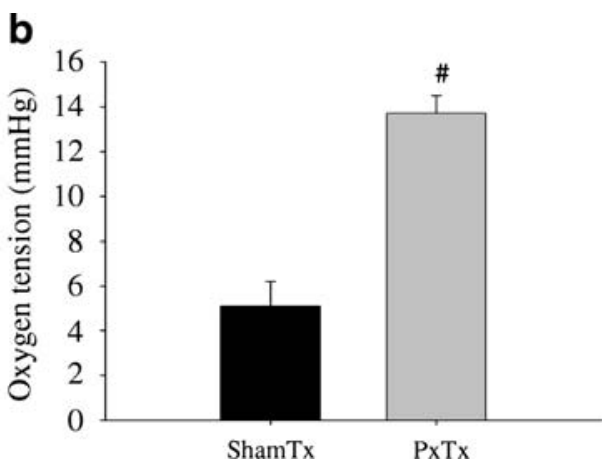

sham surgery (ShamTx), syngeneic transplantation with previous pancreatectomy $(P x T x)$, pancreatectomy followed by autotransplantation of retrieved islets $\left(\right.$ AutoTx) $p<0.05\left(^{*}\right)$ vs native islets; $p<0.05$ (\#) vs ShamTx

portion, and was similar to the oxygen tension in the control group (data not shown).

Human islets transplanted into sham-operated C57BL/6 $(n u / n u)$ mice had an oxygen tension similar to that of transplanted rat islets (control transplanted group) when investigated 1-month post-transplantation (Fig. 1b). When implanted in partially pancreatectomised recipients, the oxygen tension of the transplanted human islets was markedly increased.

Blood flow The blood flow of 1-month-old rat islet grafts in autotransplanted and partially pancreatectomised recipients was increased by $\sim 50 \%$ compared with that in syngeneic control islet grafts (Fig. 2a), whereas islets of shamoperated recipients did not differ from transplanted control rats in terms of blood perfusion. The blood perfusion of the islet grafts did not vary according to the location of isolation (the splenic or duodenal portion of the pancreas), and was similar to that observed in the control group (data not shown). The blood perfusion of grafts composed of human islets implanted in partially pancreatectomised

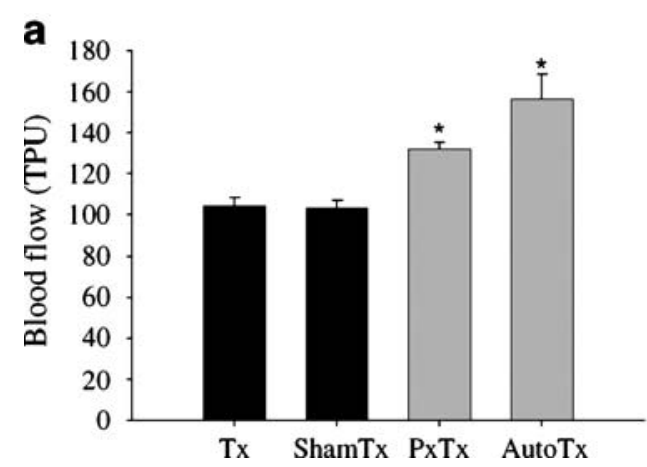

Fig. 2 Blood flow in transplanted rat islets (a) and human islets transplanted into $n u / n u$ mice (b) as measured by laser-Doppler flowmetry day 30 post-transplantation. Experimental groups: syngeneic transplantation $(T x)$, syngeneic transplantation with previous sham b

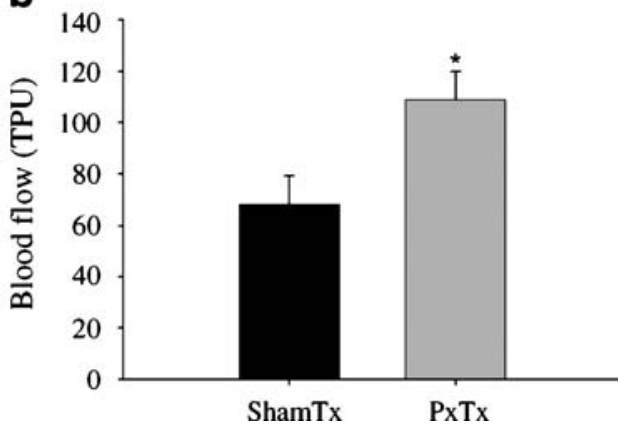

surgery (ShamTx), syngeneic transplantation with previous pancreatectomy $(P x T x)$, pancreatectomy followed by autotransplantation of retrieved islets $($ AutoTx). $p<0.05(*)$ vs ShamTx. Flow values are presented as tissue perfusion units (TPU) 
recipients was also increased when compared with corresponding islets implanted in sham-operated recipients (Fig. 2b).

Blood vessel density Blood vessels represented approximately $12 \%$ of rat native islet volume, but only $5-6 \%$ in $1-$ month-old syngeneic control rat islet transplants (Fig. 3). The graft vascular density in autotransplanted and partially pancreatectomised recipients was, however, restored 1 month post-transplantation, and was thus markedly higher than in the control grafts. Sham-operated rats receiving syngeneic islets had values similar to those of transplanted control animals. The vascular density of the islet grafts did not vary according to the location of isolation (the splenic or duodenal portion of the pancreas), and was similar to that observed in the control group (data not shown). The vascular density in the graft connective tissue stroma surrounding each implanted islet was similar in all experimental groups (data not shown).
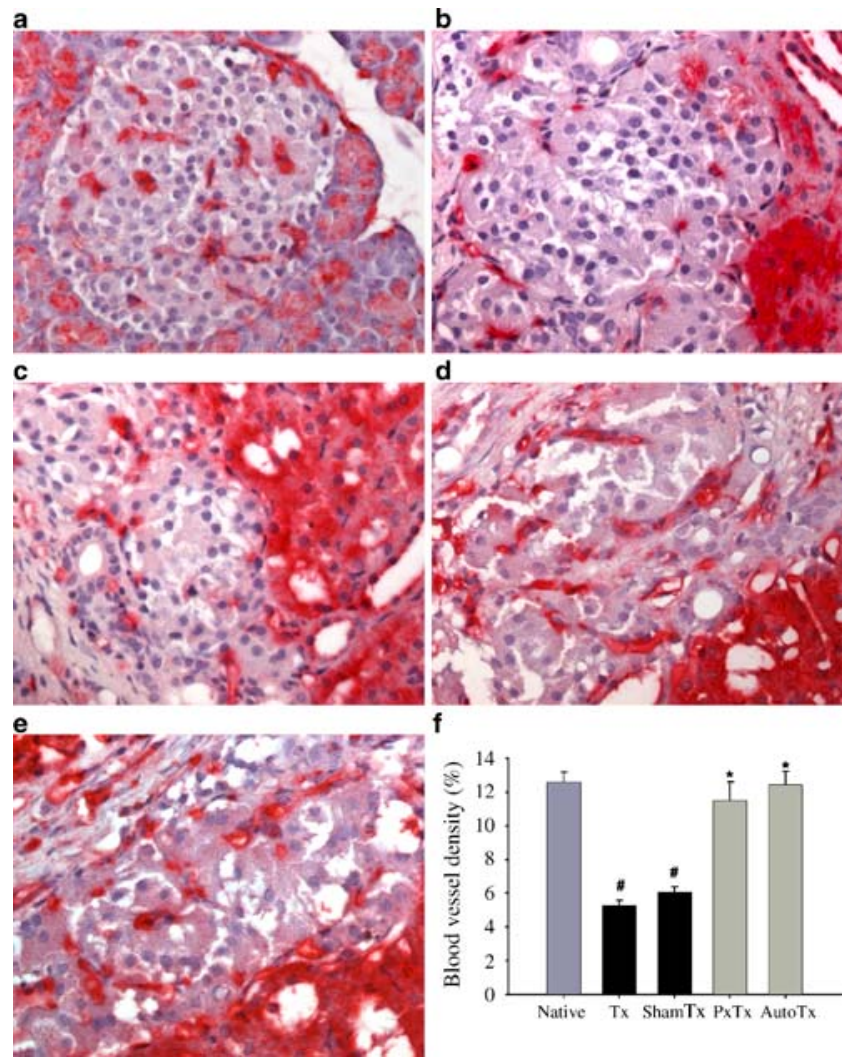

Fig. 3 Blood vessel density in native and transplanted rat islets. The transplanted islets were investigated at day 30 post-transplantation. Representative micrographs for native islets (a), syngeneic transplantation $(T x ; \mathbf{b})$, syngeneic transplantation with previous sham surgery (ShamTx; c), syngeneic transplantation with previous pancreatectomy (PxTx; d), pancreatectomy followed by autotransplantation of retrieved islets (AutoTx; e). f Estimated vascular density in the different groups. $p<0.05(*)$ vs ShamTx; $p<0.05(\#)$ when vs native islets
The proportion of islet volume taken up by blood vessels in native human islets was approximately $8 \%$ when evaluated as BS-1- or UE-positive structures (Fig. 4). In contrast, blood vessels only constituted $4-5 \%$ of the islets in the human islet transplants given to sham-operated recipients. The vascular density of human islets implanted into partially pancreatectomised recipients was higher than that in the control islet transplants and was similar to that in native islets. The higher blood vessel density in transplants of partially pancreatectomised recipients seemed to be the result of a combination of increased ingrowth of recipient blood vessels and an expansion of donor endothelial cells, since both the number of BS-1-positive/UE-negative structures (indicative of recipient blood vessels) and BS-1positive/UE-positive structures (indicative of donor blood vessels) increased, although only the latter increase reached statistical significance.
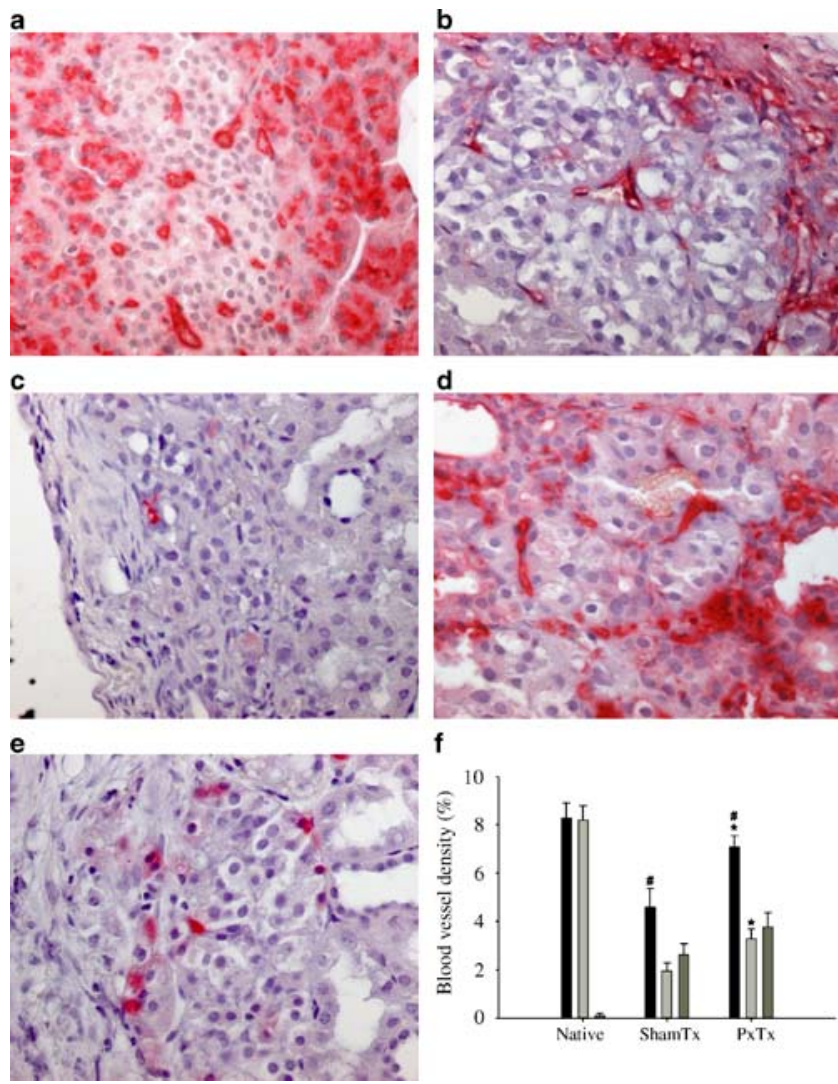

Fig. 4 Blood vessel density in native and transplanted human islets at day 30 post-transplantation. The endothelial cells were stained with BS1, to visualise all endothelial cells, or UE, for identification of human (donor) blood vessels. Representative micrographs of native islets (a), syngeneic transplantation with previous sham surgery (ShamTx; b, c) and syngeneic transplantation with previous pancreatectomy $(P x T x ; \mathbf{d}$, e). Blood vessels (red) in parts $\mathbf{a}, \mathbf{b}$ and $\mathbf{d}$ were stained with BS-1, and those in parts c and e were stained with UE. f Graph to show the estimated vascular density in the different groups. Black bars BS-1positive vessels; light-grey bars UE-positive vessels; dark-grey bars UE-negative vessels. $p<0.05\left(^{*}\right)$ vs ShamTx; $p<0.05$ (\#) vs native islets 


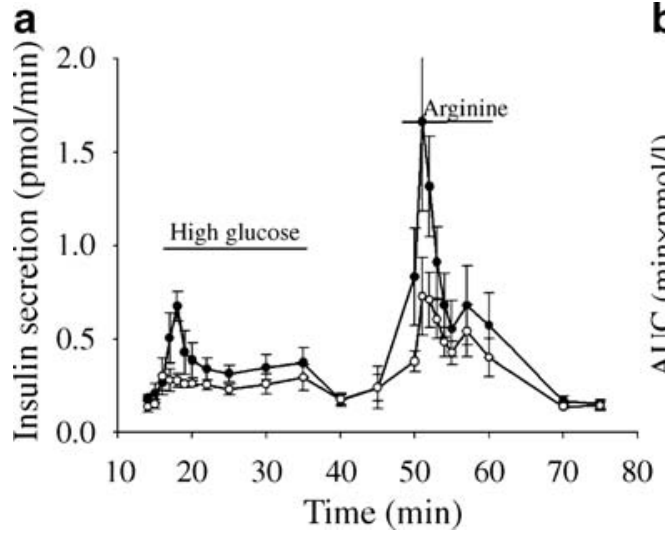

Fig. 5 a Insulin secretion in response to high glucose and arginine during perfusions of graft-bearing rat kidneys. b AUC for insulin release after stimulation with high glucose or arginine. The transplanted rat islets were investigated at 30 days post-transplantation.

Graft perfusion A distinct first- and second-phase insulin release was observed in response to high glucose stimulation in 1-month-old rat islet grafts of sham-operated control recipients (Fig. 5a). These grafts also responded to arginine. However, corresponding rat islet grafts implanted in partially pancreatectomised recipients released comparatively more insulin in response to either of these stimuli (Fig. 5b). First-phase insulin release during high glucose stimulation was markedly improved, with peak values more than twice as high as those of control grafts $(129 \pm 17$ vs $275 \pm$ $50 \mathrm{pmol}$ insulin $/ 1, p=0.016$, for grafts of sham-operated and partially pancreatectomised recipients, respectively).

Beta cell proliferation, apoptosis and islet graft volume Both at day 5 and day 30 after transplantation, partially pancreatectomised recipients of syngeneic rat islets had a higher graft endocrine volume than corresponding shamoperated control animals (Fig. 6a). The endocrine volume of 1-month-old autotransplanted grafts in rats was similar to that in partially pancreatectomised animals, whereas control recipients receiving syngeneic rat islets had an endocrine volume similar to that seen in sham-operated animals (365 \pm 45 and $248 \pm 15 \mathrm{nl}$ for autotransplanted and transplanted control animals, respectively).

Beta cell (Fig. 6b,c) and total endocrine cell proliferation (data not shown) were increased in 2-day-old islet grafts of sham-operated rats as compared with both islet grafts of partially pancreatectomised recipients and native islets. However, endocrine cell apoptosis was also markedly increased in 2-day-old grafts of sham-operated control rats when compared with both corresponding grafts of partially pancreatectomised recipients and native islets (Fig. 6d,e). At days 5 and 30 after transplantation, proliferation and apoptosis rates were similar in both groups, and did not differ from native islets. b

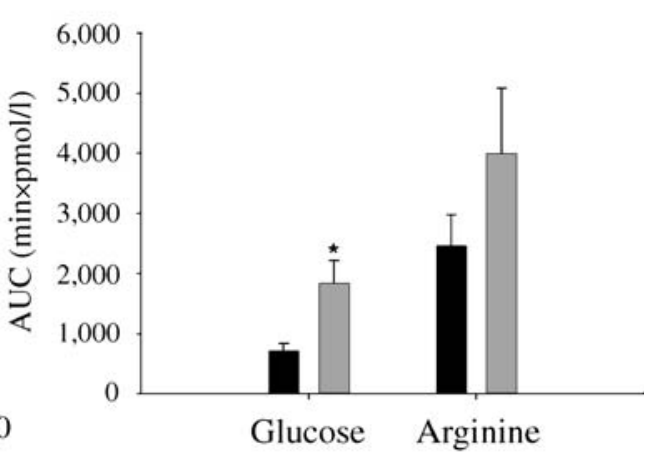

Experimental groups: syngeneic transplantation with previous sham surgery (open diamonds; black bars) and syngeneic transplantation with previous pancreatectomy (closed diamonds; grey bars). $p<0.05$ $\left(^{*}\right)$ vs syngeneic transplantation with previous sham surgery

Plasma VEGF Plasma VEGF was increased in pancreatectomised rats at day 2 after transplantation when compared with sham-operated animals $(131 \pm 12$ vs $95 \pm 11 \mathrm{pg} / \mathrm{ml}, p<0.05)$.

\section{Discussion}

This study tested the hypothesis that removal of parts of the pancreas per se would affect the revascularisation and function of islet grafts. Because we wanted to avoid the confounding effects of immunosuppressive drugs or immune reactions on islet revascularisation [7], beta cell survival and proliferation rates [33], we chose to use syngeneic or immunocompromised recipients as control groups. We also chose to use normoglycaemic recipients in the study, and therefore performed only a $60 \%$ pancreatectomy instead of a near-total pancreatectomy, as performed in clinical cases [14] and some experimental models [34]. The rationale for this was that we deemed it difficult to reproducibly design a control group with chemically induced diabetes in which blood glucose concentrations and remaining beta cell mass in control and study groups would be the same. Variable blood glucose concentrations between groups may not have influenced the vascular density of the islet transplants [35], but such differences would most probably have affected both islet survival and function [36-38]. We chose the renal subcapsular site to enable us to perform the in vivo studies. However, considering that islets implanted intraportally in the liver are located downstream of the pancreas, any factors released from the gland would be expected to reach such transplanted islets at even higher concentrations, at least prior to islet revascularisation [39]. We therefore deem the results obtained in the present study as pertinent to intraportally transplanted islets. 


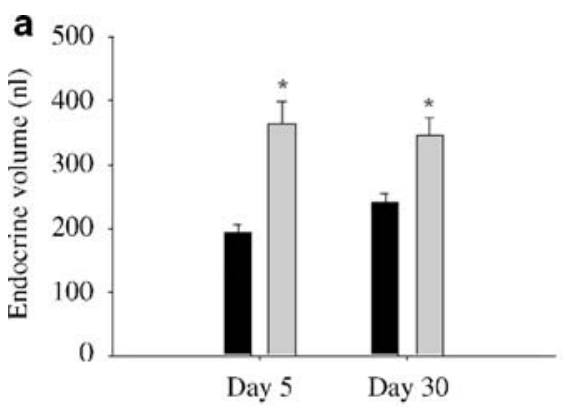

Day after transplantation

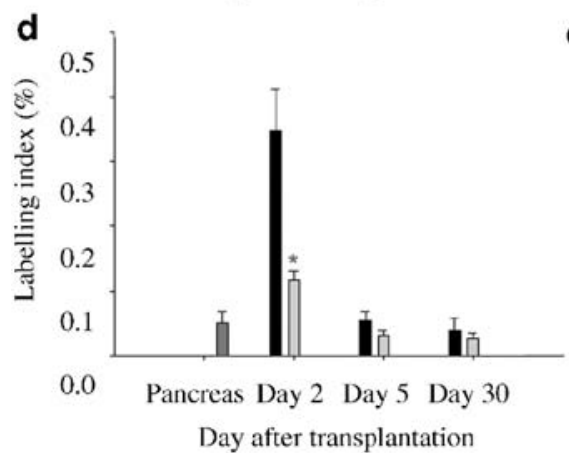

Fig. 6 Endocrine volume (expressed as nanolitre, nl) of rat islet grafts day 5 and 30 post-transplantation (a), beta cell labelling index in native rat islets and in rat islet grafts at days 2, 5 and 30 post-transplantation using the cell proliferation marker Ki67 (b), micrograph of a 2-day-old rat islet transplant stained for insulin (red) and Ki67 (brown) (c), endocrine cellular apoptosis rates in native rat islets and in rat islet

Pancreatic islets normally have a dense capillary network, which is of importance for the provision of oxygen and nutrients, to allow accurate glucose sensing, and for the release of hormones into the systemic circulation. Recent evidence also indicates an important role for islet endothelial cell products in sustaining beta cell function [40] and growth [29, 40]. Following transplantation, islets require rapid and adequate revascularisation for their survival and optimal function. Irrespective of whether implanted into the kidney, spleen or liver of normo- or hyperglycaemic recipients, experimentally transplanted rodent and human islets seem to become insufficiently revascularised $[8,9,35]$. Instead, a rich vascular network is formed in the graft stroma surrounding individual transplanted islets [8]. In the present study, the vascular density within the transplanted islets was selectively increased in partially pancreatectomised recipients. Moreover, the systemic concentration of VEGF was increased 2 days after pancreatectomy. VEGF is an important stimulator of islet angiogenesis [41, 42]; it inhibits beta cell apoptosis and increases insulin secretion of transplanted islets [43]. VEGF has also been shown to mobilise endothelial progenitor cells [44], which increases revascularisation of transplanted islets [13].

An early study indicated that the vascular network of the islet graft is predominantly derived from recipient blood grafts at days 2, 5 and 30 post-transplantation, estimated by TUNEL staining (d), micrograph of a 2-day-old rat islet transplant stained with TUNEL (brown) (e). Experimental groups: syngeneic transplantation with previous sham surgery (black bars) and syngeneic transplantation with previous pancreatectomy (PxTx; grey bars). $p<0.05\left(^{*}\right)$ vs syngeneic transplantation with previous sham surgery

vessels [45]. However, in recent years it has become evident that the remaining donor endothelium may also contribute vessels, at least if freshly isolated islets are used for transplantation [46, 47]. In the present study, the use of not only BS-1 to stain endothelium, but also a lectin specific for human endothelium, UE, enabled us to determine the relative contribution of donor and recipient endothelium to the islet vascular system in the different experimental groups. We deduced that an expansion of the donor endothelial pool occurred in the partially pancreatectomised recipients, but that there also tended to be an increased ingrowth of recipient blood vessels in these recipients as compared with sham-operated recipients. The expansion of donor endothelial cells did, however, seem to be the predominant effect of the pancreatectomy.

The increased vascular density of autologously or syngeneically transplanted islets in partially pancreatectomised recipients was associated with increased graft blood perfusion. The laser-Doppler technique measures the blood flow in both stromal and endocrine compartments of the grafts. Since the majority of the blood vessels are situated in the graft stroma, the changes in blood perfusion were expected to be less prominent than the changes in islet blood vessel density.

The improved vascular density and blood perfusion of islets implanted in partially pancreatectomised recipients 
were also reflected by the markedly improved oxygenation of such islets. However, in contrast to the vascular density, the oxygenation of the transplanted islets was not fully restored. This may reflect a less than optimal vascular organisation in transplanted islets relative to native islets. A vascular dysfunction with altered blood flow regulation has also been reported in transplanted islets [48].

Islet graft function was evaluated and compared by perfusion of graft-bearing kidneys. This enabled us to study islet transplant function isolated from the function of the native pancreas in these normoglycaemic recipients. Moreover, the technique allowed the first and second phases of glucose-stimulated insulin release to be evaluated separately. One-month-old grafts obtained from partially pancreatectomised recipients responded to stimulation with either high glucose or arginine with a much better insulin release than grafts obtained from sham-operated control recipients. This increase in total insulin output can most probably be explained by the higher endocrine mass in the former grafts. We did not detect higher rates of beta cell or total endocrine cell proliferation in grafts implanted in partially pancreatectomised recipients; instead, these values were paradoxically decreased as compared with those in shamoperated rats 2 days after transplantation. However, the endocrine cell apoptosis was markedly lower in the grafts of partially pancreatectomised recipients early after transplantation. Thus, the increased endocrine mass in grafts in partially pancreatectomised recipients seemed to depend on the release of survival signals, e.g. VEGF, GLP-1 or REG, from the surgically manipulated pancreas. A better level of revascularisation may contribute to increased islet cell survival, but this is unlikely to be the sole explanation at only 2 days post-transplantation.

The grafts of partially pancreatectomised recipients seemed to have a preferentially increased first phase of insulin release in response to high glucose or arginine as compared with control islet grafts. Interestingly, we recently observed that islets implanted into the kidney and the liver both have a decreased first phase of insulin release in response to glucose as compared with native islets [39]. This impaired insulin release in control islet grafts may reflect disturbances in the secretory machinery of beta cells $[49,50]$. It should be noted that islet endothelial cells can directly stimulate beta cell insulin secretion through paracrine effects [40]. Additionally, an acute increase in graft oxygen tension, through stimulation of blood perfusion, of islet renal subcapsular grafts has been shown to improve the first phase of glucose-stimulated insulin release [48].

In conclusion, rat and human islets implanted in partially pancreatectomised recipients become much better revascularised and oxygenated than when transplanted into control or sham-operated recipients. The improved vascular engraftment was also correlated with an improved capacity for insulin release and a larger endocrine volume. Our results provide an additional explanation, besides diminished immunological responses, for the much better outcome of clinically performed islet autotransplantations in which the recipient is pancreatectomised prior to transplantation.

Acknowledgements The technical assistance of B. Bodin, A. Nordin and E. Törnelius is gratefully acknowledged. Thanks to O. Korsgren (Department of Clinical Immunology, Uppsala University, Uppsala, Sweden) and P. Westermark (Department of Pathology, Uppsala University) for generously providing isolated human islets and human pancreas samples, respectively. The study was supported by the Juvenile Diabetes Research Foundation, the Swedish Research Council (72XD-15043, 72X-109, P2-M), the European Foundation for the Study of Diabetes (EFSD)/the Juvenile Diabetes Research Foundation (JDRF)/Novo Nordisk Programme 2006, the Swedish Diabetes Association, the Swedish Juvenile Diabetes Fund, Novo Nordisk Insulin Fund, the Anér Foundation and the Family Ernfors Fund.

Duality of interest This work involved no duality of interest.

\section{References}

1. Shapiro AM, Lakey JR, Ryan EA et al (2000) Islet transplantation in seven patients with type 1 diabetes mellitus using a glucocorticoidfree immunosuppressive regimen. N Engl J Med 343:230-238

2. Ryan EA, Lakey JR, Paty BW et al (2002) Successful islet transplantation: continued insulin reserve provides long-term glycemic control. Diabetes 51:2148-2157

3. Sutherland DE (1997) Pancreas transplantation as a treatment for diabetes: indications and outcome. Curr Ther Endocrinol Metab 6:496-499

4. Humar A, Kandaswamy R, Granger D, Gruessner RW, Gruessner AC, Sutherland DE (2000) Decreased surgical risks of pancreas transplantation in the modern era. Ann Surg 231:269-275

5. Ryan EA, Paty BW, Senior PA et al (2005) Five-year follow-up after clinical islet transplantation. Diabetes 54:2060-2069

6. Menger MD, Jaeger S, Walter P, Feifel G, Hammersen F, Messmer K (1989) Angiogenesis and hemodynamics of microvasculature of transplanted islets of Langerhans. Diabetes 38(Suppl 1):199-201

7. Jansson L, Carlsson PO (2002) Graft vascular function after transplantation of pancreatic islets. Diabetologia 45:749-763

8. Mattsson G, Jansson L, Carlsson PO (2002) Decreased vascular density in mouse pancreatic islets after transplantation. Diabetes 51:1362-1366

9. Carlsson PO, Palm F, Mattsson G (2002) Low revascularization of experimentally transplanted human pancreatic islets. J Clin Endocrinol Metab 87:5418-5423

10. Carlsson PO, Palm F, Andersson A, Liss P (2001) Markedly decreased oxygen tension in transplanted rat pancreatic islets irrespective of the implantation site. Diabetes 50:489-495

11. Zhang N, Richter A, Suriawinata J et al (2004) Elevated vascular endothelial growth factor production in islets improves islet graft vascularization. Diabetes 53:963-970

12. Lai Y, Schneider D, Kidszun A et al (2005) Vascular endothelial growth factor increases functional beta cell mass by improvement of angiogenesis of isolated human and murine pancreatic islets. Transplantation 79:1530-1536

13. Contreras JL, Smyth CA, Eckstein C et al (2003) Peripheral mobilization of recipient bone marrow-derived endothelial progenitor cells enhances pancreatic islet revascularization and engraftment after intraportal transplantation. Surgery 134:390-398 
14. Oberholzer J, Triponez F, Mage R et al (2000) Human islet transplantation: lessons from 13 autologous and 13 allogeneic transplantations. Transplantation 69:1115-1123

15. Lee BW, Jee JH, Heo JS et al (2005) The favorable outcome of human islet transplantation in Korea: experiences of 10 autologous transplantations. Transplantation 79:1568-1574

16. Robertson RP, Lanz KJ, Sutherland DE, Kendall DM (2001) Prevention of diabetes for up to 13 years by autoislet transplantation after pancreatectomy for chronic pancreatitis. Diabetes 50:47-50

17. Oberg-Welsh C, Sandler S, Andersson A, Welsh M (1997) Effects of vascular endothelial growth factor on pancreatic duct cell replication and the insulin production of fetal islet-like cell clusters in vitro. Mol Cell Endocrinol 126:125-132

18. Anneren C (2002) Dual role of the tyrosine kinase GTK and the adaptor protein SHB in beta cell growth: enhanced beta-cell replication after $60 \%$ pancreatectomy and increased sensitivity to streptozotocin. J Endocrinol 172:145-153

19. Laybutt DR, Glandt M, Xu G et al (2003) Critical reduction in beta cell mass results in two distinct outcomes over time. Adaptation with impaired glucose tolerance or decompensated diabetes. J Biol Chem 278:2997-3005

20. De Leon DD, Deng S, Madani R, Ahima RS, Drucker DJ, Stoffers DA (2003) Role of endogenous glucagon-like peptide- 1 in islet regeneration after partial pancreatectomy. Diabetes 52: 365-371

21. Baeza N, Moriscot C, Figarella C, Guy-Crotte O, Vialettes B (1996) Reg protein: a potential beta-cell-specific growth factor? Diabetes Metab 22:229-234

22. Dvorak HF, Brown LF, Detmar M, Dvorak AM (1995) Vascular permeability factor/vascular endothelial growth factor, microvascular hyperpermeability, and angiogenesis. Am J Pathol 146:1029-1039

23. Lu L, Holmqvist K, Cross M, Welsh M (2002) Role of the Src homology 2 domain-containing protein $\mathrm{Shb}$ in murine brain endothelial cell proliferation and differentiation. Cell Growth Differ 13:141-148

24. Baudino TA, McKay C, Pendeville-Samain H et al (2002) c-Myc is essential for vasculogenesis and angiogenesis during development and tumor progression. Genes Dev 16:2530-2543

25. Jansson L, Sandler S (1989) Pancreatic and islet blood flow in the regenerating pancreas after a partial pancreatectomy in adult rats. Surgery 106:861-866

26. Andersson A (1978) Isolated mouse pancreatic islets in culture: effects of serum and different culture media on the insulin production of the islets. Diabetologia 14:397-404

27. Eizirik DL, Korbutt GS, Hellerström C (1992) Prolonged exposure of human pancreatic islets to high glucose concentrations in vitro impairs the beta cell function. J Clin Invest 90:1263-1268

28. Carlsson PO, Liss P, Andersson A, Jansson L (1998) Measurements of oxygen tension in native and transplanted rat pancreatic islets. Diabetes 47:1027-1032

29. Johansson M, Mattsson G, Andersson A, Jansson L, Carlsson PO (2006) Islet endothelial cells and pancreatic beta-cell proliferation: studies in vitro and during pregnancy in adult rats. Endocrinology 147:2315-2324

30. Korsgren O, Jansson L, Sandler S, Andersson A (1990) Hyperglycemia-induced B cell toxicity. The fate of pancreatic islets transplanted into diabetic mice is dependent on their genetic background. J Clin Invest 86:2161-2168

31. Welsh N, Margulis B, Borg LA et al (1995) Differences in the expression of heat-shock proteins and antioxidant enzymes between human and rodent pancreatic islets: implications for the pathogenesis of insulin-dependent diabetes mellitus. Mol Med $1: 806-820$
32. Korsgren O, Jansson L, Andersson A (1989) Effects of hyperglycemia on function of isolated mouse pancreatic islets transplanted under kidney capsule. Diabetes 38:510-515

33. Andersson A, Korsgren O, Kojima Y, Mellgren A, Sandler S, Swenne I (1985) Experimental studies of transplantation and regeneration of endocrine pancreatic cells. Acta Paediatr Scand Suppl 320:26-31

34. Bonner-Weir S, Trent DF, Weir GC (1983) Partial pancreatectomy in the rat and subsequent defect in glucose-induced insulin release. J Clin Invest 71:1544-1553

35. Mattsson G, Jansson L, Nordin A, Carlsson PO (2003) Impaired revascularization of transplanted mouse pancreatic islets is chronic and glucose-independent. Transplantation 75:736-739

36. Davalli AM, Scaglia L, Zangen DH, Hollister J, Bonner-Weir S, Weir GC (1996) Vulnerability of islets in the immediate posttransplantation period. Dynamic changes in structure and function. Diabetes 45:1161-1167

37. Jansson L, Eizirik DL, Pipeleers DG, Borg LA, Hellerström C, Andersson A (1995) Impairment of glucose-induced insulin secretion in human pancreatic islets transplanted to diabetic nude mice. J Clin Invest 96:721-726

38. Biarnes M, Montolio M, Nacher V, Raurell M, Soler J, Montanya E (2002) Beta-cell death and mass in syngeneically transplanted islets exposed to short- and long-term hyperglycemia. Diabetes 51:66-72

39. Lau J, Jansson L, Carlsson PO (2006) Islets transplanted intraportally into the liver are stimulated to insulin and glucagon release exclusively through the hepatic artery. Am J Transplant 6:967-975

40. Nikolova G, Jabs N, Konstantinova I et al (2006) The vascular basement membrane: a niche for insulin gene expression and beta cell proliferation. Dev Cell 10:397-405

41. Inoue M, Hager JH, Ferrara N, Gerber HP, Hanahan D (2002) VEGF-A has a critical, nonredundant role in angiogenic switching and pancreatic beta cell carcinogenesis. Cancer Cell 1:193-202

42. Lammert E, Gu G, McLaughlin M et al (2003) Role of VEGF-A in vascularization of pancreatic islets. Curr Biol 13:1070-1074

43. Stagner J, Mokshagundam S, Wyler K et al (2004) Beta-cell sparing in transplanted islets by vascular endothelial growth factor. Transplant Proc 36:1178-1180

44. Asahara T, Takahashi T, Masuda H et al (1999) VEGF contributes to postnatal neovascularization by mobilizing bone marrowderived endothelial progenitor cells. EMBO J 18:3964-3972

45. Vajkoczy P, Olofsson AM, Lehr HA et al (1995) Histogenesis and ultrastructure of pancreatic islet graft microvasculature. Evidence for graft revascularization by endothelial cells of host origin. Am J Pathol 146:1397-1405

46. Linn T, Schneider K, Hammes HP et al (2003) Angiogenic capacity of endothelial cells in islets of Langerhans. FASEB J 17:881-883

47. Brissova M, Fowler M, Wiebe P et al (2004) Intraislet endothelial cells contribute to revascularization of transplanted pancreatic islets. Diabetes 53:1318-1325

48. Kampf C, Lau T, Olsson R, Leung PS, Carlsson PO (2005) Angiotensin II type 1 receptor inhibition markedly improves the blood perfusion, oxygen tension and first phase of glucosestimulated insulin secretion in revascularised syngeneic mouse islet grafts. Diabetologia 48:1159-1167

49. Shi CL, Taljedal IB, Nordin A, Andersson A (2000) Human islets transplanted to nude mice: in vitro insulin release from retrieved grafts. Ups J Med Sci 105:193-206

50. Mattsson G, Jansson L, Nordin A, Andersson A, Carlsson PO (2004) Evidence of functional impairment of syngeneically transplanted mouse pancreatic islets retrieved from the liver. Diabetes 53:948-954 